
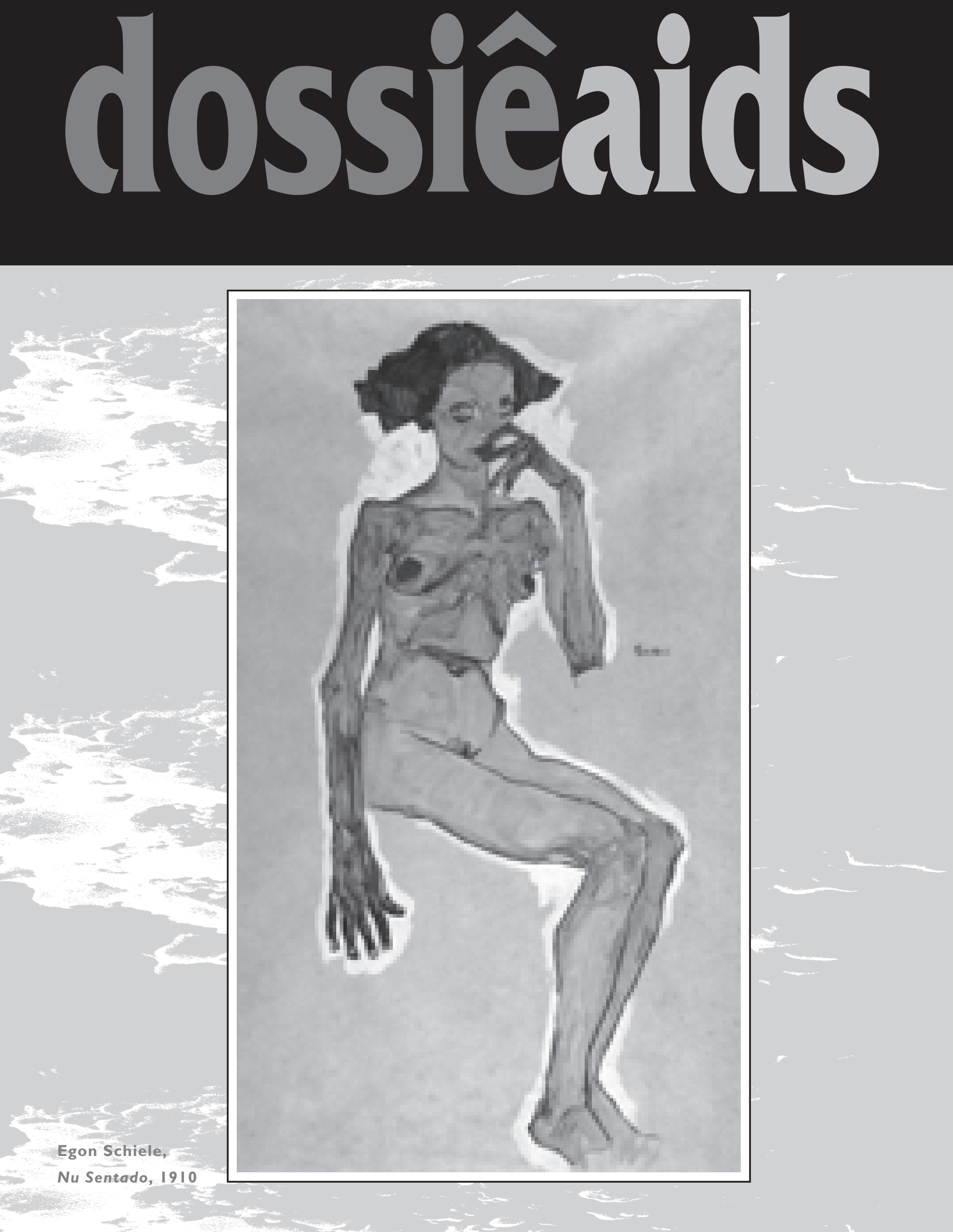

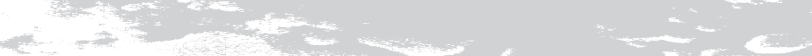

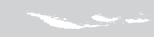



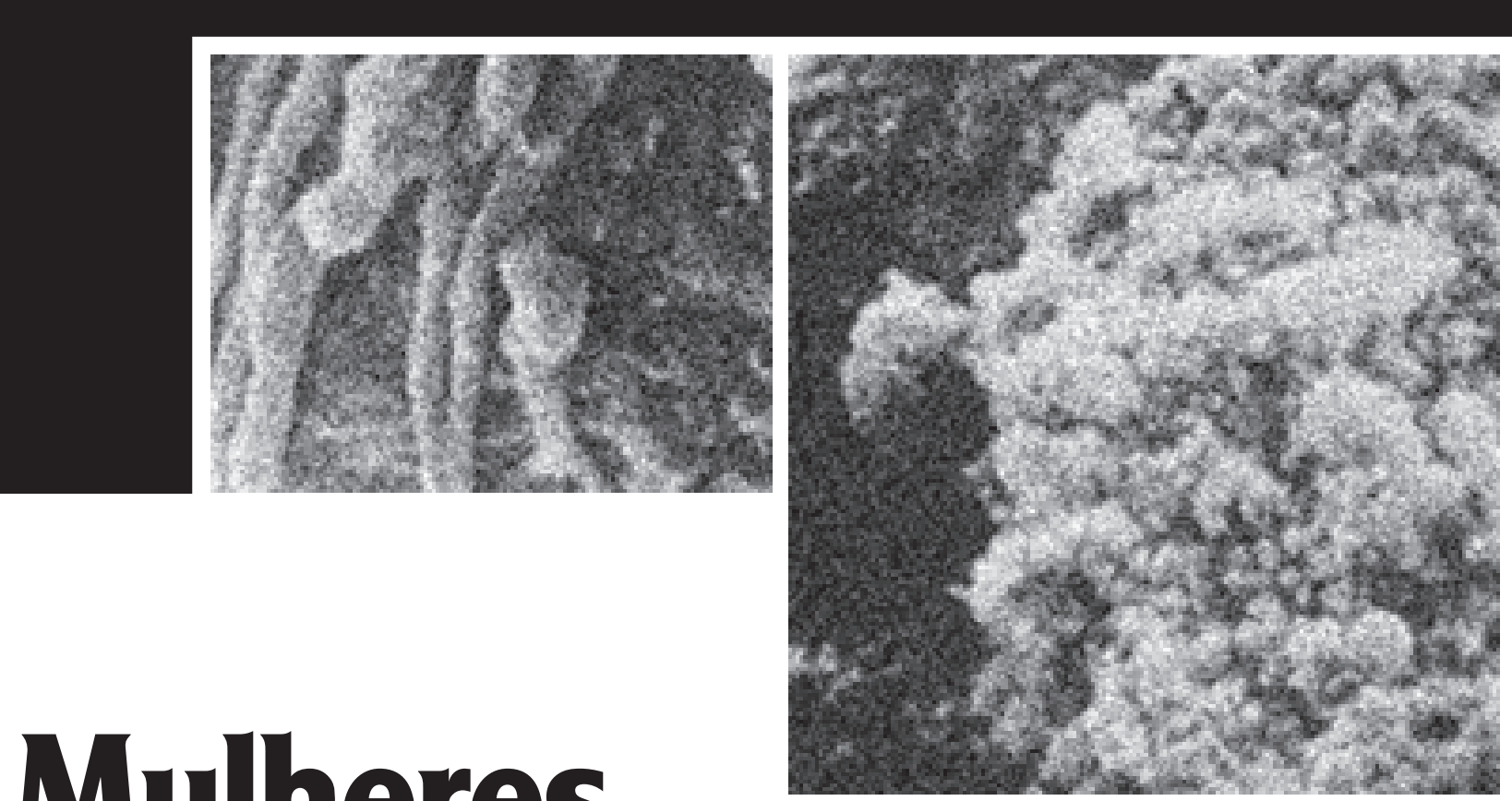

DE N ISE MARTIN

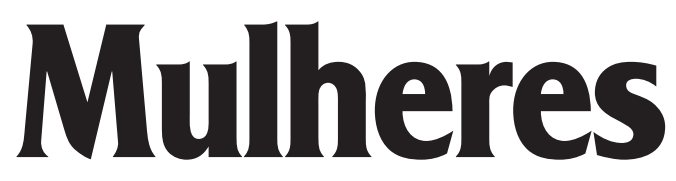

\section{e Aids: uma abordagem antropológica}

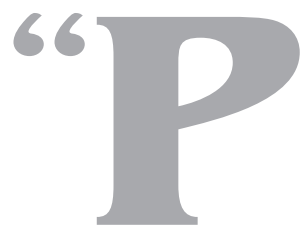

ara mulher solteira, para prosti-

tuta, para homossexual. Não para a mulher casada. Eu achava que a mulher casada estaria longe disso. Que não poderia acontecer um caso de Aids entre uma mulher casada. Uma mulher que tinha o seu esposo, que tinha um só relacionamento. Eu achava que a Aids aconteceria com mulheres de vários parceiros. E para homens de várias parceiras, para homossexuais, não para a mulher casada, não para a esposa, não para aquela

DENISE MARTIN é doutoranda em Antropologia Médica no Departamento de Antropologia da FFLCH-USP.

Este trabalho teve o apoio da Fapesp - Fundação de Amparo à Pesquisa do Estado de São Paulo. 
I Neste trabalho, a diferença entre a condição de ser portador do HIV e de ser pesso com Aids está no desenvolvimento prévio de sintomas.

2 Os dados aqui apresentados são parte dos resultados da dissertação de mestrado: "Mulheres e Aids: uma Abordagem Antropológica", defendida na FFLCH-USP em maio de 1995.

3 No Brasil, em 1983, a razão homem para mulher (casos de Aids) era de 40 para I, respectivamente. Em 1994, havia 3 homens com Aids para cada mulher, proporção que vem se mantendo até o momento (1996). Fonte: Ministério da Saúde, Programa Nacional de Doenças Sexualmente Transmissíveis e Aids, Aids - Boletim Epidemiológico, Ano IX, no 3 , Semana Epidemiológica 23 35 - junho a agosto, 1996

4 No período de 1980 a 1995 a principal categoria de risco para mulheres era o contato heterossexual (43,3\%), seguido por uso de drogas $(30,8 \%$, transmissão vertical $(7,8 \%)$ sangue e seus derivados $(3,9 \%)$ e forma de transmissão em investigação (14,1\%) de todos os casos no Brasil. Fonte: Ministério da Saúde. Programa Nacional de Doenças Sexualmente Transmissíveis e Aids, Aids - Boletim Epidemiológico, número especial, agosto de 1995

5 No período de 1980 a 1994 o coeficiente de incidência em Santos (taxa por 100.000 habitantes) é 445,2, sendo o segundo mais alto do país, superado apenas pela cidade de tajaí (SC), também portuária. Fonte: Ministério da Saúde, Programa Nacional de Doenças Sexualmente Transmissíveis e Aids, Aids - Boletim Epidemiológico, Ano IX, n I, Semana Epidemiológica 49 a 05 - dez./95 a fev/196.

6 Fontes: Ministério da Saúde Programa Nacional de Doenças Sexualmente Transmissíveis e Aids, Aids - Boletim Epidemiológico, número especial, agosto de 1995; Prefeitura Municipal de Santos - Se cretaria de Higiene e Saúde. Centro de Controle de Doenças. Sistema de Avaliação Controle da Aids, Boletim Epidemiológico № 20, fev./96.

7 Somente foram entrevistadas mulheres que consentiram em conversar sobre o assunto.

8 A categoria "casada" incluitanto mulheres unidas legalmente com seus companheiro como as uniões consensuais.
Compreender o que é a Aids vai muito além de saber de sua existência, formas de contágio e prevenção. Embora a informação seja um item fundamental nas práticas de prevenção à Aids, sendo até uma clara questão de cidadania, ela não é suficiente para desencadear imediatamente as desejadas mudanças de comportamento no sentido de conter a epidemia.

O objetivo deste artigo é mostrar alguns aspectos da realidade vivida por mulheres portadoras do HIV ou com Aids (1), mostrando a complexidade da prevenção da doença nesse grupo.

A forma escolhida para tratar o assunto toca, simultaneamente, em desafios e perspectivas. A compreensão da maneira como as mulheres entendem a situação da contaminação revela alguns desafios importantes na prevenção da Aids nesse grupo social. Contudo, essas mesmas dificuldades sugerem perspectivas para uma intervenção a partir da experiência descrita por essas mulheres. Ao entrar nessa realidade, estranha e obscura para alguns, pretendese tornar compreensível por que algumas mulheres se contaminaram, ou melhor, o que era importante para elas e o que a Aids significa em suas vidas.

Um pressuposto fundamental para o entendimento dessa questão é fugir de explicações que culpariam ou vitimizariam essas mulheres. As explicações do senso comum, que justificam a contaminação por ignorância ou burrice, não cabem nesta forma de tratar o assunto.

A abordagem aqui proposta, fundamentada teoricamente na antropologia, busca compreender o contexto cultural da contaminação de mulheres pelo HIV. Foram abordados vários aspectos: o que pensavam sobre a Aids antes da contaminação, como entendem o fato de terem sido contaminadas por seus companheiros; a opinião que têm sobre eles; se imaginavam a possibilidade de serem contaminadas; como imaginam a prevenção da Aids e, por fim, como justificam sua situação atual... Esta maneira de tratar a questão permitiu entrar em contato com o cotidiano de mulheres vivendo com o HIV/Aids, revelando, ain- da que de maneira contraditória, como entendem a situação em que se encontram.

Participaram da pesquisa (2) mulheres já contaminadas pelo vírus da Aids, o HIV, por meio de uma relação sexual, excluindo-se as profissionais do sexo (prostitutas), as usuárias de drogas endovenosas e as que receberam transfusão de sangue. Tal escolha se justifica, em primeiro lugar, pelo fato de que as mulheres vêm representando um importante aumento no número de infecções pelo HIV (3) e, em segundo lugar, pelo tipo de exposição e risco que essa população corre (4). O grupo escolhido se expõe à contaminação por via sexual em situações concretas do cotidiano, tais como namoro, casamento, ou mesmo relacionamento sexual eventual.

A pesquisa foi realizada em 1994, no município de Santos, cidade portuária localizada no litoral paulista com uma das maiores incidências de casos de Aids no país (5). Em Santos, a incidência de casos entre mulheres é igual à média nacional: para cada três homens, há uma mulher contaminada. A categoria de transmissão mais importante entre as mulheres, tanto em nível nacional como local, é a sexual (6). Portanto, pesquisando mulheres em Santos pretende-se mostrar um pouco sobre as mulheres com Aids no nosso país.

Foram entrevistadas dezesseis mulheres (7), pacientes do Centro de Referência de Aids de Santos (Craids), e sua descrição revela que elas têm em comum poucas características, exceto o fato de serem HIV positivo ou terem Aids e a forma de contaminação ter sido por relação sexual. Havia grande diferenciação quanto à opção religiosa, condições socioeconômicas, nível de organização da vida cotidiana e número de parceiros sexuais. Quanto ao relacionamento com os parceiros, havia mulheres casadas (8) (período de vida em comum compreendido entre 3 e 34 anos), viúvas (há quatro anos ou menos) e solteiras (que se contaminaram num relacionamento afetivo esporádico).

A bibliografia sobre mulheres e Aids já ressaltava muitas questões importantes sobre as dificuldades da prevenção da do- 


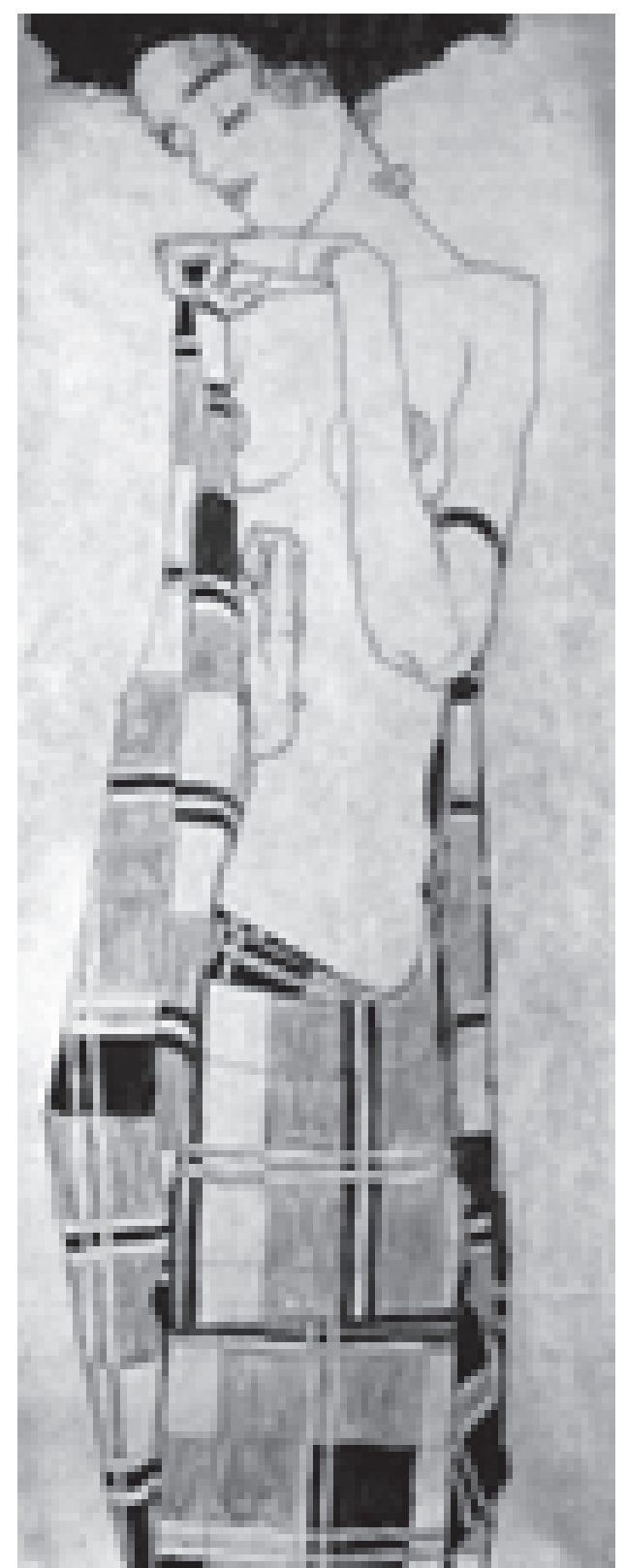

ença nessa população. Os obstáculos são de várias ordens: a dificuldade da mulher exigir do parceiro o uso da camisinha; o não-questionamento sobre o comportamento do parceiro; a crença na capacidade das mulheres de conhecerem seus parceiros; a importância da fidelidade e da confiança; o fato de as mulheres já usarem outro método de contracepção; o questionamento do comportamento do companheiro poder levar ao abuso verbal, violência ou perda do parceiro; a dependência financeira do parceiro; a crença de que a camisinha reduz o prazer sexual; o tabu de falar sobre sexo; o fato de a mulher pedir para usar camisinha poder significar uma condenação de seu próprio comportamento; o não-uso da camisinha significar o desejo de uma relação estável; a associação do uso da camisinha com comportamentos desviantes e imorais... (9).

Enfim, esses argumentos mostram que o sexo inseguro, longe de ser uma atitude irresponsável e limitada ao fato de não entrar em contato com o HIV, está fortemente ancorado na forma como as relações de gênero se estabelecem socialmente.

Tendo como pressuposto que várias dessas dificuldades estavam presentes no contexto do relacionamento com seus parceiros, procuramos compreender a realidade de mulheres contaminadas pelo HIV pela relação sexual numa abordagem que buscasse a lógica que dá sentido, do ponto de vista cultural, a esta nova situação em que elas se encontram.

Com a Aids, um destino social novo delineou-se na vida dessas mulheres. A partir dessa realidade concreta, será analisado como elas elaboram a situação de contaminação e a doença em seu cotidiano, isto é, como vão enriquecendo o conceito (Aids) e firmando comportamentos que passam a ser reconhecidos como corriqueiros. A Aids vai entrando para a cultura.

\section{DEFINIÇÕES DA AIDS (ANTES E DEPOIS DA CONTAMINAÇÃO)}

A Aids é um acontecimento dramático na vida das mulheres entrevistadas. A constatação de uma doença de prognóstico ainda reservado, associada à discriminação, preconceito, sofrimento físico e psíquico, é uma situação difícil e delicada na vida dessas pessoas.

Ainda que a doença pudesse fazer parte do repertório de preocupações de algumas das mulheres entrevistadas, nenhuma delas considerava a possibilidade concreta de contaminação. Os fatos negativos na vida das pessoas não são previstos e calculados na mesma medida em que os desejos, os sonhos e os planos. A forma como as mulheres pensavam a Aids antes de saberem
Egon Schiele,

Rapariga

Envolvida num

Tecido aos

Quadrados, I9I8 


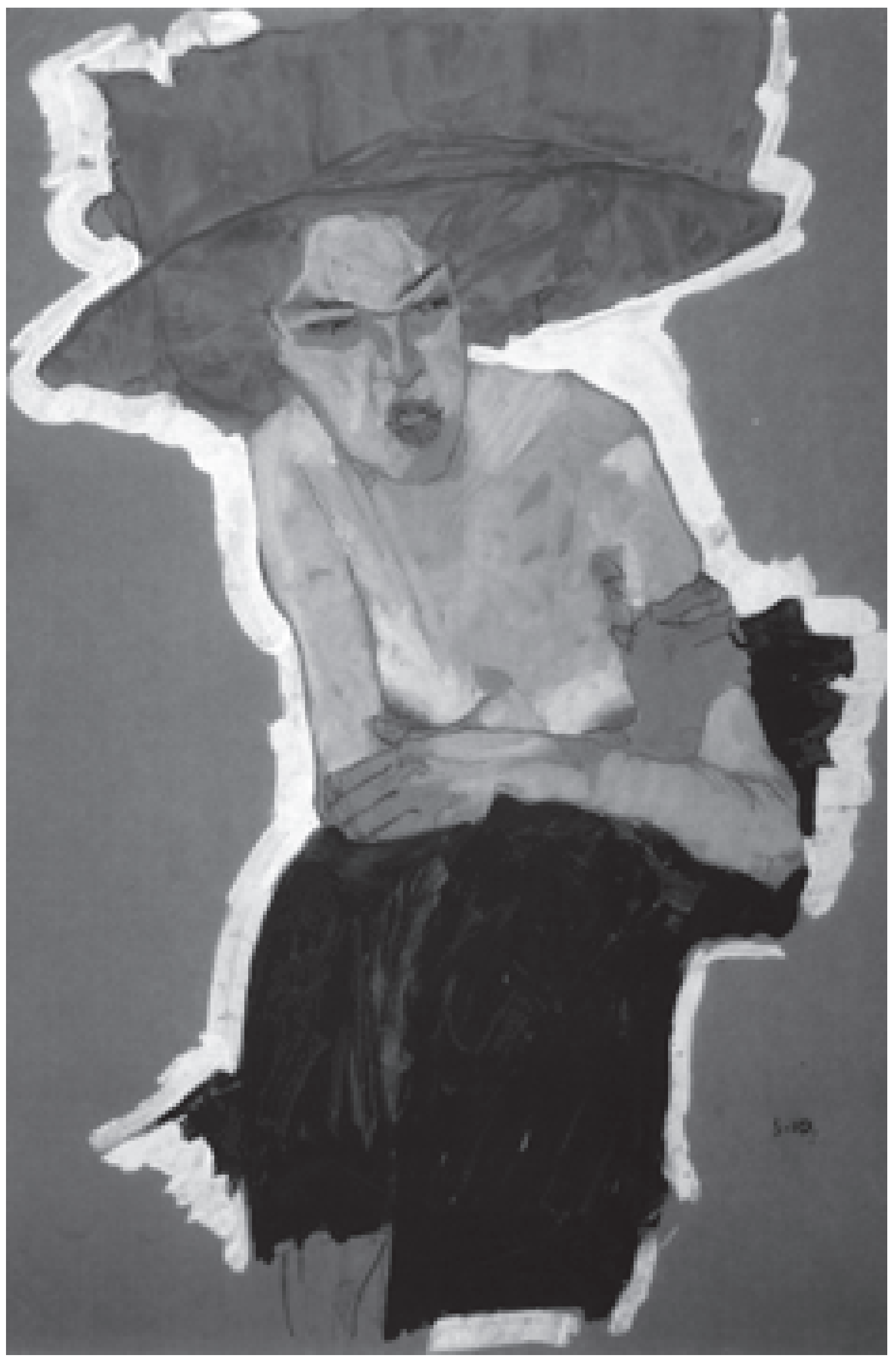


da contaminação, ou seja, o que era e para quem era a doença, pode revelar os estereótipos da Aids que elaboram (ou escolhem) dentre os disponíveis.

Várias justificativas são dadas pelas mulheres para a não-preocupação com a Aids, como no seguinte depoimento: “Eu achava que eu estava imune. Imagina que eu ia me contaminar! Não uso drogas, não tenho mais que um parceiro, então, eu achava isso o cúmulo" (A. P., 37, casada, segundo grau completo).

A Aids era, definitivamente, a doença do outro, fosse ele homossexual, alguém com vários parceiros, mulher solteira, prostituta, ou usuário de drogas... A associação com os "grupos de risco" é evidente, mostrando como a construção cultural da doença ainda se associa às pessoas que inicialmente se contaminaram. É possível que esse tipo de argumento esteja relacionado na ênfase dada, no início da epidemia, à categoria "grupos de risco" (10). De qualquer forma, a Aids só poderia acontecer com pessoas cujo comportamento é considerado muito diferente do das mulheres entrevistadas nesta pesquisa.

O “outro", passível de se contaminar, é também aquele cujo comportamento desviante torna inteligível o contágio. A não-preocupação com a Aids está relacionada a um código moral no qual o casamento ou um relacionamento afetivo parece garantir "imunidade" à doença. Tratase, portanto, de um sistema classificatório que delimita claramente quem pode ter Aids, associado à promiscuidade, ao comportamento desviante, à vida desregrada, e quem não pode: mulheres "com tudo certinho", com um só parceiro, onde a afetividade e o amor são uma constante. Essas justificativas revelam estereotipias de compreensão da doença, como se fosse uma imagem fixa, invariável e homogênea. No nível consciente, Aids equivaleria a homossexual, drogado e homens e mulheres com muitos parceiros, e outras tantas características que se afastam (e ameaçam) do ideal de afeto e amor com um só parceiro.

A Aids não se concretizava como uma ameaça. A imagem inicial da doença se apresenta como uma realidade distante e inatingível, às vezes com a aparência irreal, como se fosse uma coisa que não existisse de fato, um alarme falso. Se considerarmos que a doença era associada ao "outro", a preocupação com uma possível contaminação não existiria.

Se a análise parasse neste ponto, chegaríamos ao seguinte raciocínio: se as entrevistadas tivessem conhecimento da doença, teriam se prevenido. Contudo, a realidade é muito mais complexa e mostra como as contradições presentes nos discursos das mulheres entrevistadas revelam um sistema lógico muito distante desse tipo de argumentação.

A maioria das entrevistadas não pensava na possibilidade da contaminação pelo HIV. Para elas, a doença era uma coisa que poderia, novamente, acontecer só com os outros e jamais com elas:

"Me balançou, mexeu comigo, mexeu com a minha estrutura, mexeu com a minha família, mexeu com os meus filhos. Mexeu com tudo. Foi uma coisa assim que eu pensei que eu ia morrer no dia seguinte. Foi uma coisa tão... eu? com Aids? Mas por que eu? Na hora eu pensei, não só 'por que eu'? mas ‘por que nós'?” (N., 31, casada, primeiro grau incompleto).

Este tipo de argumentação foge à racionalidade da medicina que explica a contaminação pelo contato com o vírus. A dúvida "por que eu?" ou a certeza de que pode acontecer somente com os outros são argumentos que, por mais que fossem explicados pela racionalidade, não seriam suficientes como resposta à situação atual dessas mulheres. Não basta somente o médico constatar a presença de um vírus, é preciso também entender como precisamente elas estão com esse vírus.

O questionamento "mas por que eu?", formulado como explanação da injustiça, revela um sistema de classificação no qual os contaminados pelo HIV devem ter culpa pelo que lhes aconteceu. Se elas não se consideram culpadas, acabam assumindo
Ao lado, Schiele,

A Maliciosa, I9I0

10 Para Singer, a etnografia contribuiu para mostrar como as categorias epidemiológicas em que são enquadrados os chamados "grupos de risco" são vagas e como é problemático usá-las como base para esforços de prevenção diretos. $\mathrm{O}$ uso de categorias "homossexual" e "usuário de drogas" é equivocado, e esses grupos não podem se tratados como homogêneos. M. Singer, "Aids and the Health Crisis in the U.S. Urban Poor: the Perspective of Critical Medical Anthropology", in Socia Science and Medicine, vol. 39 no 7, pp. 931-48. 


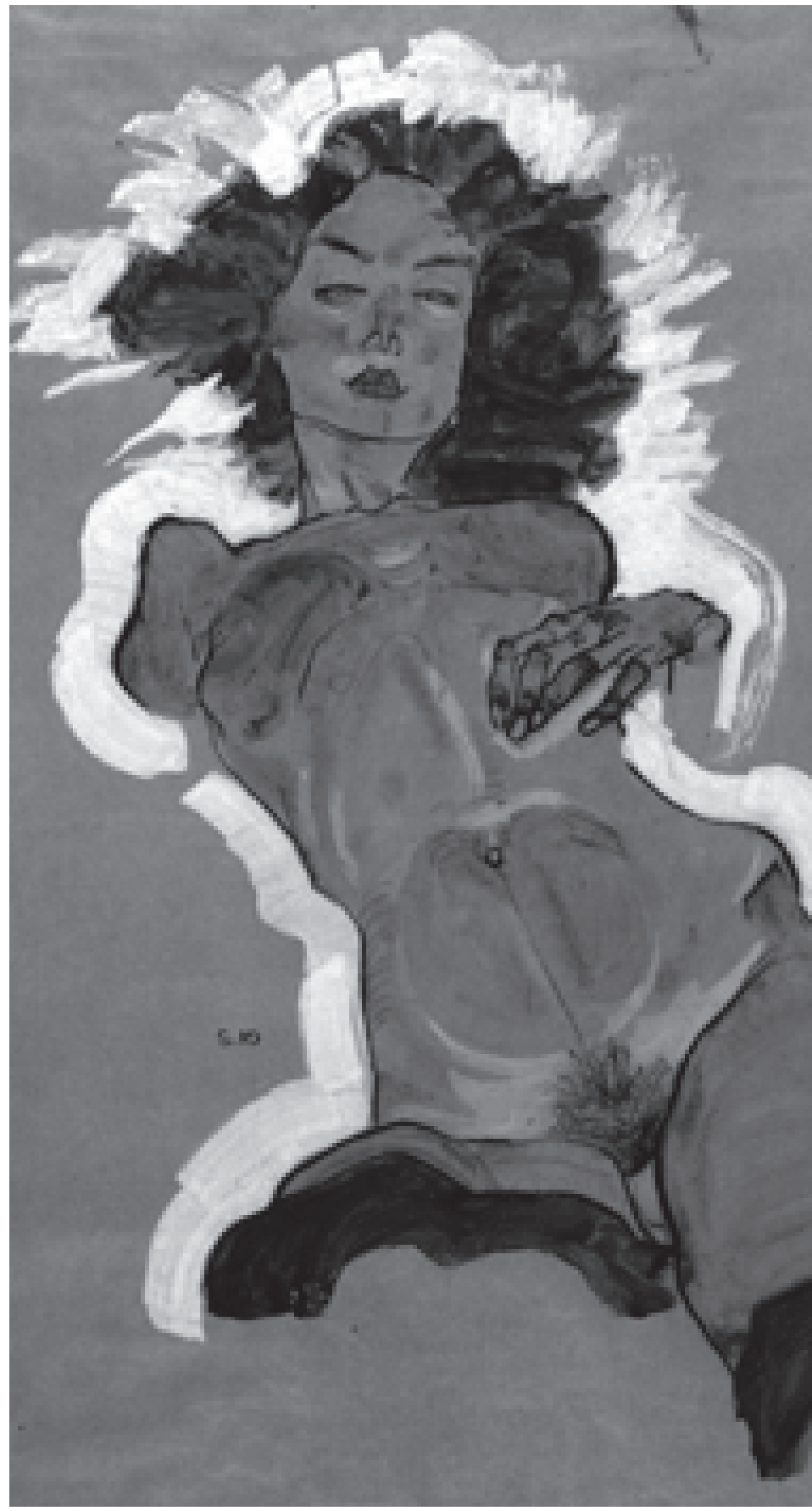

Egon Schiele, Mulher Nua, I 9 I 0 o papel de vítimas: "eu não fiz nada”, "não tenho nada a dever..., não tenho nada a ver com essa história de Aids".

Nesse nível das elaborações das justificativas da contaminação encontram-se as razões, no consciente, da contaminação e como compreendem a realidade a partir da vivência da doença. Esse pensamento é sempre posterior ao fato, sugerindo uma reelaboração "explicativa" das coisas.
A justificativa da contaminação não pode se prender às estereotipias da doença. Se elas não se enquadram no padrão anteriormente citado, é necessário inventar uma nova forma de ver a doença:

"O meu namorado que eu estou há dois anos, graças a Deus ele não tem problema, ele não é soropositivo, já fez exame, mas eu tenho o maior cuidado para não passar isso para ele e nem também para ninguém. Não quero, não porque seja a pior doença do mundo, porque tem o câncer também que é muito ruim, mas a pior doença está na cabeça das pessoas, a pessoa ser maldosa, fazer isso com todo mundo. De repente você olha para mim e diz: ela não tem nada. Ninguém vai imaginar que uma pessoa saudável tem o vírus, só vai se manifestar algum tempo, ou então demore a se apresentar..." (M., 26, solteira, segundo grau incompleto).

A doença do outro, estigmatizante e vergonhosa, é agora a doença do cotidiano dessas mulheres. A condição de soropositivo ou doente de Aids faz com que ocorra uma reelaboração das representações sobre a doença. A classificação social do mundo realizada por elas coloca a distância os aspectos negativos da sociedade, impondo um impasse: como incorporar essa realidade indigna e impura ao cotidiano? A solução para o problema se dá num processo de vulgarização e purificação da Aids. De doença impura, restrita a grupos considerados desvalorizados socialmente, a Aids passa a ser, para essas mulheres, uma doença que pode acontecer com qualquer um, mais uma doença, que nãoé a pior coisa que pode acontecer no mundo, porque outras doenças também matam, como a violência mata, o atropelamento... Portanto, não é mais a doença do outro, poluída, mas um acontecimento que pode atingir qualquer um. Se qualquer um está vulnerável à doença, significa que ela foi banalizada no contexto das doenças (ou das coisas ruins). Dessa forma, legitima-se a contaminação.

As contradições presentes nas entrevis- 
tas, tais como "a Aids era uma doença de desviantes e agora é uma doença de qualquer um", mostram como as representações sobre a doença não são estáticas e elaboram-se em função de experiências concretas e vão se enriquecendo (e mudando). Tais "desencontros" revelam que a análise das representações sociais não pode se limitar à mera descrição dos fatos, mas buscar a lógica subjacente ao discurso de quem fala.

\section{COMO ELES SE CONTAMINARAM?}

Como toda doença transmissível, a Aids pressupõe a presença de um outro. O resultado positivo do teste implica, necessariamente, investigar quem transmitiu o vírus e a forma como se contaminou. No caso das mulheres entrevistadas, contaminadas por via sexual por seus parceiros, seria de se esperar que elas indagassem a forma como eles se contaminaram. O Craids mantém sigilo sobre as informações do pré-teste, que contém a forma como os companheiros se contaminaram. Portanto, para essas mulheres entenderem por que estão doentes, seria necessário perguntar para o parceiro como ele se contaminou. Essa questão foi abordada pelas entrevistadas de variadas formas, como mostra o seguinte depoimento: "Não cheguei não, eu nem quero conversar com ele... Não, se eu perguntar para ele, ele vai me dar pancada, então eu não converso sobre isso com ele" (A., 26, solteira, primeiro grau completo).

Para algumas entrevistadas, o tipo de relacionamento com o companheiro, fundamentado na submissão e na falta de diálogo, impossibilitou conversar sobre como eles se contaminaram, mostrando como a doença se insere num cotidiano já estabelecido, onde não necessariamente as regras são mudadas em função da Aids.

Outro aspecto interessante é a forma como elas imaginam que eles se contaminaram: "Perguntei sim, ele mesmo me falou que não sabia. Porque ele disse que não usava drogas, mas como ele bebia muito, tenho as minhas dúvidas sabe. Ele bebia tanto, talvez tivesse tido relação com alguma mulher" (M., 32, viúva, primeiro grau incompleto).

As justificativas para a contaminação do companheiro excluem qualquer possibilidade de questionamento de sua virilidade. Ainda que uma das formas de transmissão do vírus à mulher seja porque o companheiro é bissexual, essa hipótese não foi cogitada pelas entrevistadas. Se entrar em contato com o HIV significa relacionar aspectos negativos da sociedade, existem alguns que são mais legítimos e menos vergonhosos do que outros. No discurso dessas mulheres, o contágio pela prostituição é uma forma legítima de se contaminar, uma vez que reforça a imagem viril do companheiro e, ao mesmo tempo, o inocenta, porque ele poderia nem saber que estava se contaminando.

É preciso então entender o que aconteceu com elas, por que estão nessa situação, seja pela negação do conhecimento da via de transmissão do companheiro, seja justificando pela vida promíscua anterior ao relacionamento com elas ou mesmo querendo perguntar como deixaram uma coisa dessas acontecer. De qualquer forma,é preciso elaborar a situação da contaminação.

\section{A INOCÊNCIA DO COMPANHEIRO}

Um aspecto importante dessa "compreensão" da Aids é a forma como elas pensam a contaminação pelo HIV e o sentimento em relação ao companheiro. Nenhuma das entrevistadas abandonou o companheiro por causa da doença. Nos casos em que houve separação, os motivos foram justificados por desentendimentos no relacionamento. As falas das entrevistadas os inocentam da contaminação pelas mais variadas justificativas:

“Aí, depois de muitos anos, seis anos só, arrumei o pai da menina. Foi quando herdei essa coisa. Coitado dele, nem sabia também. Todo mundo diz que eu não devia ter 
apoiado ele até o fim. A família dele se afastou, ninguém quis saber. Ficou abandonado. Eu fiquei com ele o tempo todinho. Trazia ele para fazer tratamento aqui, para ficar internado. A família dele se afastou completamente, tinha medo da doença. Eu achava que ele não tinha culpa também. Se ele soubesse não passava para mim, porque as pessoas não sabem" (M., 32, viúva, primeiro grau incompleto).

A inocência dos companheiros, seja ela real ou fictícia, é uma categoria de compreensão da situação em que se encontram. A Aids, estando associada a conotações negativas do ponto de vista social, não pode ser conectada diretamente à realidade dessas mulheres. Para tal, os companheiros, pessoas com quem se envolveram afetivamente, não podem ser os vilões dessa história mórbida. De alguma forma, a Aids também entrou em suas vidas sem querer, o que justifica a nãointencionalidade da contaminação. Os parceiros mantinham práticas de risco para a infecção pelo HIV sem que, necessariamente, as parceiras soubessem.

\section{JOGANDO COM A SORTE, JOGANDO COM A VIDA...}

O grupo das mulheres entrevistadas pode ser dividido em dois quanto ao conhecimento do risco de se contaminar pela Aids: as que se contaminaram por acidente, que não imaginavam sequer a possibilidade de os companheiros terem práticas de risco, e as que, de alguma forma, desconfiavam da possibilidade da contaminação dos companheiros. Essa divisão se fundamenta no conhecimento de práticas de risco dos companheiros e não no nível de informação sobre a doença das entrevistadas.

Para as mulheres que se contaminaram por acidente, a doença foi, simultaneamen-

Na outra página,

Schiele,

Nu com Cabelos

Negros, 1910 te, uma surpresa e a descoberta de práticas de risco dos companheiros até então desconhecidas. Geralmente, a contaminação é justificada pelo uso de drogas ou por sair com mulheres, num passado em que não viviam com as atuais companheiras.

O fato de a doença permanecer assintomática por um período indeterminado também possibilita que o conhecimento da doença seja tardio ou mesmo que permaneça oculto o maior tempo possível, seja deliberadamente ou não.

No caso das outras mulheres, estar com o HIV não é necessariamente uma surpresa, pois, em diversos graus, havia o conhecimento das práticas de risco dos companheiros, como mostra o seguinte depoimento:

"Por livre e espontânea vontade eu fiz seis exames. Eu vinha aqui no Centro de Saúde e pedia para fazer os exames. Eu sabia que um dia a casa podia cair. Eu estava consciente disso, tantoé que quando a minha casa caiu, como a gente diz, eu senti, mas, eu sabia que eu não estava enganada. Eu acho que o maior engano é a gente dizer assim: eu não sabia. Eu sabia que ele usava droga, eu sabia que eu podia um dia acontecer de me contaminar" (M., 37, casada, segundo grau completo).

O conhecimento em relação ao risco, nesses casos, foi desde uma desconfiança dos comportamentos do parceiro até a busca deliberada do exame por imaginar que poderia estar contaminada. Ao nível do senso comum é de se esperar que, ao terem conhecimento de determinado risco ou perigo, as pessoas vão se precaver de entrar em contato com situações que possam ser desfavoráveis. Esses depoimentos contradizem essa argumentação, mostrando como a consciência do risco não leva, necessariamente, às desejadas mudanças de comportamento.

De alguma forma, algumas dessas mulheres tinham noção do risco que corriam e, ao mesmo tempo, não fizeram nada para evitar a contaminação:

"Não, ele nunca aceitou que se tocasse nesse assunto [camisinha]. Ele nunca, ele não admitia. Para ele isso não existia. E eu talvez por relaxamento meu, por gostar tanto dele, eu fui deixando, até que infelizmen- 
te... Eu ia fazer os exames, dava negativo. Ele falava: tá vendo? como que eu posso ter Aids se o seu é negativo? Eu não tenho. Então a gente ia jogando com a sorte. E eu fui jogando com a minha vida" (M., 37, casada, segundo grau incompleto).

Essas justificativas não podem se pautar na ignorância ou na falta de responsabilidade. Não se pode alegar que elas se contaminaram por não saber como se transmitia a doença, ou mesmo o que era a doença. Por outro lado, é difícil entender essa aparente irresponsabilidade que pode reverter em doença e sofrimento para elas próprias. Há uma lógica por trás disso que faz com que, apesar do conhecimento do risco que corriam, preferissem arriscar.

\section{AIDS E AMOR}

Saber do risco e não fazer nada parece paradoxal e absurdo aos olhos leigos. Alguns depoimentos revelam que essas atitudes, longe de serem inconseqüentes, estão fortemente ancoradas numa lógica cultural que lhes dá coerência, revelando, ainda que de forma contraditória, o contexto cultural da contaminação:

"Era ao mesmo tempo que eu sabia, que eu achava que eu podia me contaminar, eu tinha que fazer alguma coisa. $\mathrm{O}$ meu amor por ele era tanto que ele conseguia com que eu esquecesse. Porque ele dizia: isso não existe, isso é besteira. Quando eu ia fazer exame eu ficava naquela apreensão... e dava negativo. Eu pensava, ele está certo... Não existe até que acabou acontecendo. Sendo a realidade" (M., 37, casada, segundo grau incompleto).

A categoria que está presente, subjacente aos depoimentos, tornando incompatível o relacionamento e a prevenção da Aids, é fortemente ancorada na emoção e na afetividade: o amor.

$\mathrm{O}$ amor, categoria vivida de diversas maneiras, ofusca o contexto do risco e da contaminação. Há uma incompatibilidade

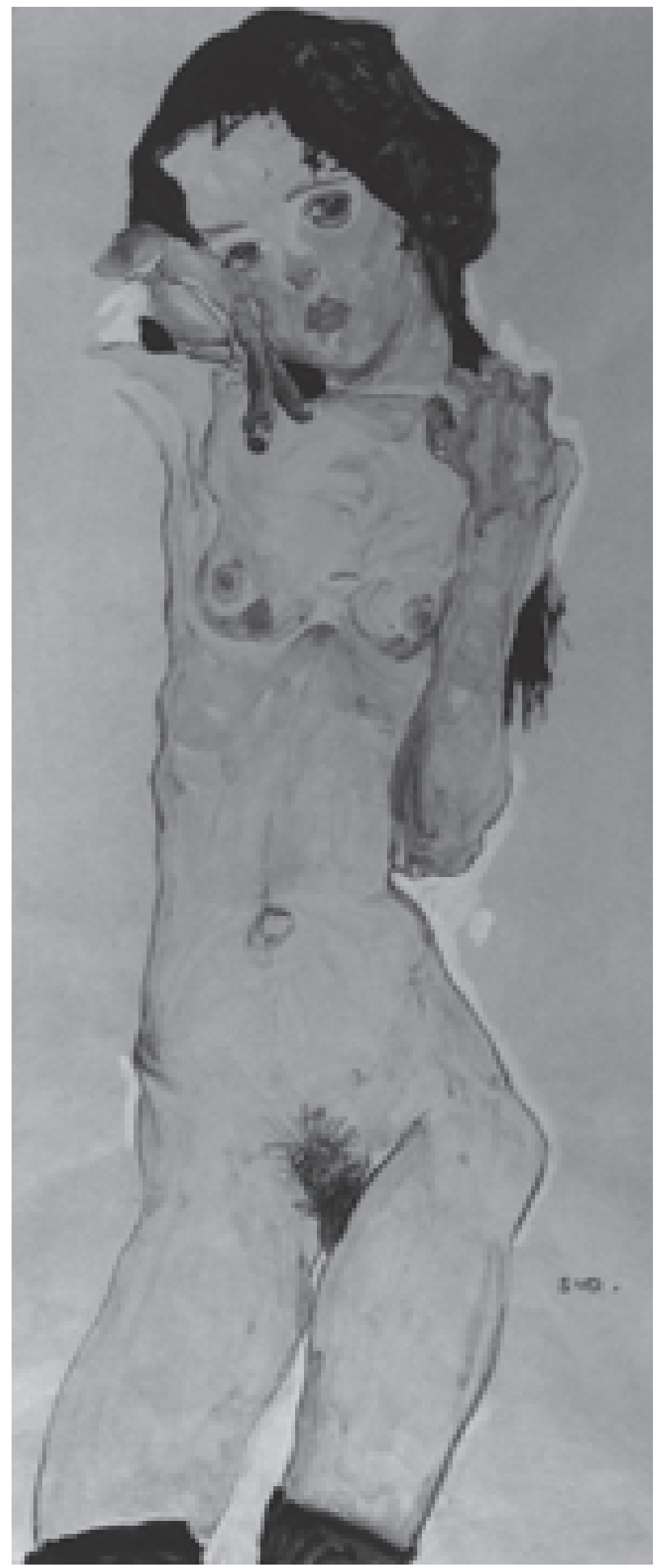


Schiele,

Nu Sentado, | 9 | 4 entre Aids e amor do ponto de vista cultural. Primeiro, a doença está relacionada a desvio, morte, dor, sofrimento... enfim, tudo o que é considerado negativo e socialmente desvalorizado. Segundo, o relacionamento amoroso implica, ainda que de maneira idealizada, felicidade, prazer, alegria, entrega... Entre essas duas categorias, existe a sexualidade, ponto de encontro entre o amor e a doença. A sexualidade faz a mediação entre essas duas possibilidades, incompatíveis do ponto de vista da cultura. Esse encontro é evitado, inconscientemente, até o momento em que ocorre a confirmação do teste.

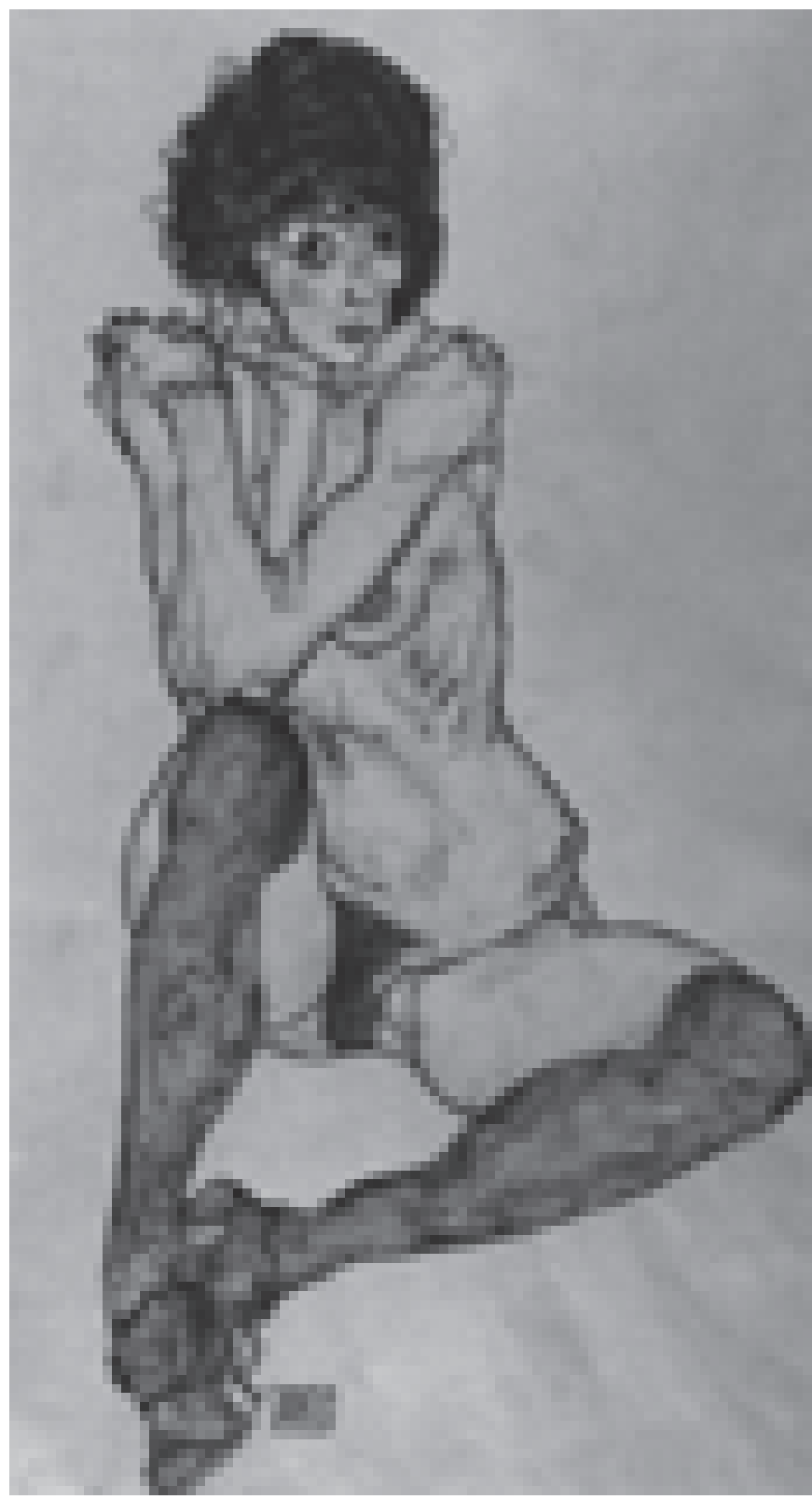

Esse modelo de interpretação permite compreender as contradições das falas dessas mulheres no tocante a diversas questões, desde o conhecimento do risco e o "não fazer nada" para evitar a contaminação, a "inocência” do companheiro, até a afirmação de que correriam o risco novamente por causa de seus companheiros. A fala de uma entrevistada mostra como essa lógica está presente:

“[...] as pessoas não pensam no risco. Sabe, como nesse caso, se eu começar a namorar legal, tal, a gente vai ter relação. Você acha que ele... ele pode até usar camisinha numa boa, ele que toma a iniciativa, se a gente continuar, você acha que daqui a seis meses ele vai usar? Não vai usar. Você acha que ele vai chegar para mim e pedir um exame? Não vai, não vai. A pessoa se arrisca. Não pensa. Você está apaixonada, você acha que a pessoa está. Eu acho, eu acho mesmo, que tirando o amor, a pessoa se contaminar é burrice. Contamina porque é burra mesmo. Se você não está envolvida com a pessoa e transa sem camisinha, é burra mesmo. Sem camisinha é atestado de idiotice mesmo. Agora se você está envolvida, é difícil mesmo" (E., 34, solteira, superior completo).

Esta fala mostra como a Aids não pode ser pensada num contexto individualizado e excluído da vida das pessoas. O fato de essas mulheres estarem contaminadas pelo HIV não implica que seja uma experiência na vida que vá derrubar toda a construção cultural da qual participam.

Outra questão importante é que não ocorreu necessariamente uma mudança em relação ao sentimento pelos companheiros devido à contaminação. Em alguns casos, o sentimento de mágoa é muito mais devido a situações concretas do cotidiano do que pelo vírus:

“O queficou deste relacionamento? - Muita mágoa, por eu não ter podido mostrar para ele que o mundo não era tão ruim, não tenho mágoa que ele me passou o HIV, mas que ele me judiou muito. [...] eu acho que 
o HIV não me fez mal, foi uma consequiência só, aconteceu, foi falta de informação, ou sei lá o que, burrice minha ou sei lá o que, entendeu? Mas aconteceu, então ela não me incomoda, enquanto eu puder cuidar dela e ela de mim a gente vai indo embora" (S., 32, viúva, primeiro grau incompleto).

A doença não mudou o sentimento em relação ao companheiro. Os desencontros e as desigualdades em relação a ele, como a falta de diálogo e a violência, são situações muito mais arraigadas no cotidiano do que a contaminação pelo HIV. Tal constatação sugere que para se pensar a Aids entre mulheres é preciso ir além das estereotipias descritas em suas falas e buscar os porquês da contaminação numa dimensão mais profunda, em que contrair Aids entre mulheres possivelmente se opõe drasticamente ao contexto em que homens contraem a doença.

\section{COMO AS MULHERES PODEM EVITAR A AIDS (POR MULHERES JÁ CONTAMINADAS)}

Uma das questões da entrevista era sobre o que a mulher poderia fazer para evitar a Aids. O objetivo era tentar abordar como mulheres que vivem a condição de portadoras do HIV ou doentes de Aids imaginariam a prevenção da doença, e conhecer como, ao pensar na vida de outras mulheres, estariam pensando no que fizeram ou não. Os conselhos dados pelas entrevistadas, na sua maioria, contradizem a realidade vivida por elas próprias:

"Acho que tomar vergonha na cara mesmo, não no sentido pejorativo, e tirar esse medo se não for usar a camisinha vai perder o homem, aquelas coisas todas, não. É diálogo mesmo, para qualquer coisa [...] é do marido para a mulher, o namorado, o parceiro, é a mesma coisa. Tem que conversar, cansar e ficar de garganta dolorida, tudo, até chegar num acordo de usar a camisinha. Se tiver medo de dialogar não vai usar. Não

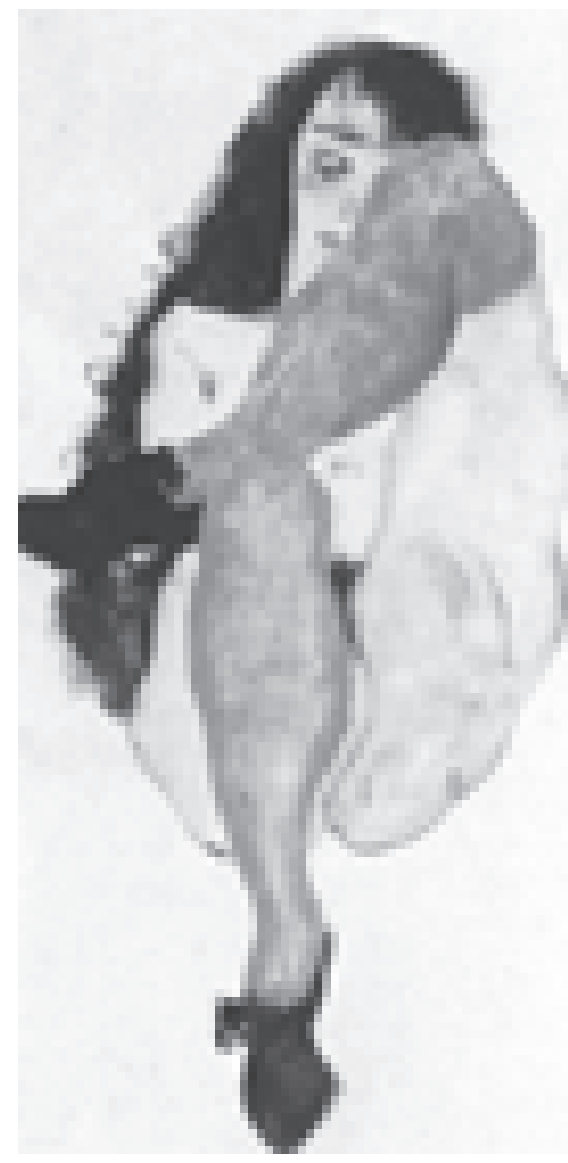

Schiele,

Nu com Meias

Verdes, I9I2 é só chegar: vamos usar a camisinha. Vamos usar a camisinha por causa disso, daquele, daquele outro. Não quer? então não posso fazer nada... Agora tem que insistir e falar e falar, e o diálogo não e só com a camisinha, tem que ser com tudo, senão para chegar na camisinha tem muita coisa para falar ainda. Eé o que menos as pessoas usam..." (S., 32, viúva).

No discurso das entrevistadas, a prevenção da doença não se restringe ao uso da camisinha, mas exige um questionamento da qualidade dos relacionamentos entre os gêneros. Falar sobre "saber com quem anda" ou "o jeito da mulher" de conseguir as coisas mostra uma lógica na qual a prevenção da Aids só é possível quando há diálogo, sinceridade, relacionamento aberto, conhecimento real do parceiro... Essas situações estão no lado oposto do contexto em que essas mulheres se contaminaram. O não-questio- 
Na outra página, Schiele, detalhe de Enlace (Par

Enlaçado II), I 9 I 7 namento sobre como os companheiros se contaminaram, o desconhecimento das práticas de risco em alguns casos, a violência presente em outros casos, mostram que, longe de terem o poder que pregam em seus conselhos, elas se contaminaram justamente pelo que não fizeram, aqui entendido como decisão não-deliberada. E o que não fizeram para se prevenir da doença não representa nenhuma exceção. Elas se contaminaram não por serem mulheres diferentes das outras, ou por estarem associadas a práticas de risco específicas ao grupo social a que pertencem. Muito pelo contrário, são mulheres com escolaridade, nível sociocultural e projetos de vida diferentes.

Tais paradoxos conduzem a análise para uma questão anterior a todas as diferenças descritas no grupo das mulheres entrevistadas, e remetem a uma reflexão sobre a condição feminina. Enfim, torna-se necessário discutir o que há por trás de tantas diferenças aparentes.

\section{CONCLUSÃO}

A lógica que essas mulheres mostraram, por meio de seus depoimentos, revela que o amor e a afetividade ocupam um lugar privilegiado do ponto de vista social, e são muito mais importantes do que um risco de contaminação sequer imaginado em seu cotidiano.

$\mathrm{O}$ amor surge como uma categoria que ofusca a possibilidade de prevenção da Aids. Porque elas amam, elas se arriscam e ao mesmo tempo perdoam, cuidam, suportam situações insuportáveis, muitas vezes associadas ao desconhecimento do comportamento do parceiro, à falta de diálogo e à violência.

Essas situações, descritas pelas mulheres entrevistadas, não representam uma realidade exclusiva do grupo pesquisado. Possivelmente, muitas mulheres estão atualmente se contaminando nas mesmas situações acima descritas: não questionando, se submetendo e, sobretudo, se arriscando. Vale lembrar que o não fazer nada para se prevenir da doença não é resultado de uma decisão individual, mas está inserido em todo um contexto sociocultural.

Este trabalho pretende mostrar que as mulheres que têm Aids hoje no nosso país não são uma categoria à parte de mulheres, que se expuseram mais ao risco, ou pobres vítimas de parceiros desonestos. Estes dados refletem a realidade da condição feminina no nosso país, onde a Aids é somente mais uma conseqüência da falta de poder da mulher na sociedade, como afirmou Sobo (11). Nesta pesquisa, essa ausência de poder revela-se no não-questionamento do comportamento do parceiro, no desconhecimento das práticas de risco, enfim, na submissão que tem como conseqüência a contaminação pelo HIV.

A pretensão deste estudo para todos que se preocupam com a prevenção da Aids entre mulheres não pode se limitar à conclusão de que a própria condição feminina impossibilita a prevenção da doença. É importante que sejam conhecidas as limitações e as dificuldades para que possam ser pensadas estratégias adequadas para atingir essa população.

Como afirmou Sobo (12), a epidemia não vai esperar que se reestruturem as relações de gênero, poder e raça. Com certeza não vamos poder mudar construções históricas e culturais, dentro das quais está a própria definição de mulher, de um dia para o outro.

É fundamental considerar que, longe de qualquer estratégia preventiva ditada por outros, é necessário dar autonomia para as mulheres refletirem sobre sua condição. Este trabalho foi uma forma de dar voz àquelas que vivem, cotidianamente, a Aids. E, se nossa análise e interpretação forem aceitáveis, conclui-se que a prevenção da doença deve passar, necessariamente, pela importância do amor e da entrega no relacionamento entre os gêneros, como sugeriram as próprias entrevistadas. Isso implica que, ao falarmos sobre prevenção da Aids entre mulheres, é preciso partir das classificações que elas próprias elaboram sobre a doença, porque é a partir daí que se chega ao que é relevante e ao que não é do ponto de vista da cultura. 


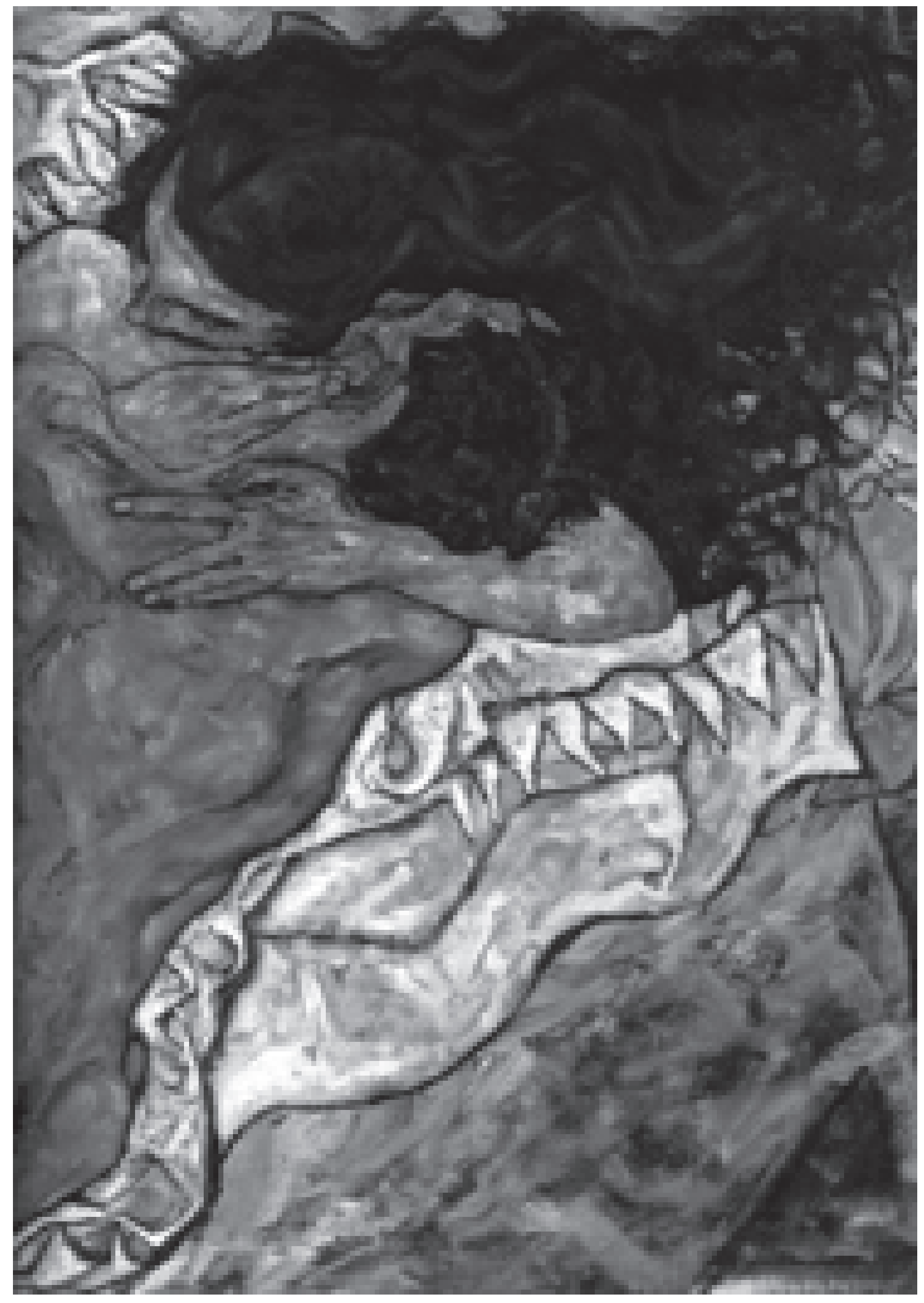

